\title{
Diffusion in gel-enzyme-linked immunosorbent assay a new serological test for leptospirosis
}

\author{
RTM CURSONS, PA PYKE \\ From the Department of Pathology, Waikato Hospital, and the Department of Bacteriology, Hamilton \\ Medical Laboratory, New Zealand
}

SUMMARY A new serological test, diffusion in gel-enzyme-linked immunosorbent assay (DIGELISA) was developed and compared with the microscopic agglutination test (MAT) for the serological diagnosis of leptospirosis. The results suggest that DIG-ELISA is a viable alternative to the MAT because of its simplicity, sensitivity, versatility and potential for standardisation.

Diagnosis of leptospirosis in humans is based on clinical, cultural or serological parameters. However diagnosis based on clinical grounds alone is considered unreliable and thus should be confirmed by either cultural isolation and/or the demonstration of a rise in specific antibody titre between acute and convalescent sera. ${ }^{2}$ Cultural isolation may be attempted from the blood or occasionally cerebrospinal fluid (CSF) during the first week of the disease. After the first week of the disease blood cultures are rarely successful and so culture must be attempted from alkalinised urine. ${ }^{1-3}$ However not infrequently, because of prior antibiotic treatment, the length of time needed for culture and the suitability of specimens for culture in relation to the course of the infection, serology remains the principle method of diagnosis.

Of all current serological tests the microscopic agglutination test (MAT) is regarded as the reference test. $^{3}$ The test is considered elaborate, expensive, time-consuming, thus remaining a specialised test of reference laboratories only. ${ }^{3}$ Furthermore the use of either living or formalised antigens and the subjectiveness in assessing the degree of agglutination can lead to considerable variation in antibody titres between laboratories using this test. As a result of variabilities in MAT titres between different laboratories becoming apparent in a survey of leptospirosis in New Zealand, the diffusion in gel-enzyme-linked immunoassay (DIG-ELISA) was investigated as an alternative test. 45

Accepted for publication 6 April 1981
Material and methods

LEPTOSPIRAL SEROVARS

Leptospira interrogans serovars hardjo and pomone (the most prevalent serovars causing human diseage : in New Zealand) ${ }^{6}$ were obtained from the Nation Health Institute, Wellington, NZ. Strains of thes serovars were cultured at $30^{\circ} \mathrm{C}$ in the dark in $\bar{\partial}$ bovine serum albumin Tween-80 medium (Difco laboratories). Thiomersal-preserved strains of the same serovars were also kindly donated by Wellcome, NZ Ltd.

\section{RABBIT ANTISERUM}

Bivalent anti-hardjo and anti-pomona serum was produced in an 8 month New Zealand White female rabbit. The rabbit was bled for pre-immune serum and then sensitised with an intramuscular injection containing $10^{9}$ of thrice washed leptospiral cells of each serovar, emulsified in a 50:50 mixture of Freunds complete adjuvant (Difco laboratories). The rabbit was then rested for 21 days, and the immunity boosted with the same concentration of leptospires but this time emulsified in Freunds in- $N$ complete adjuvant. Thereafter the rabbit was immunised with 2 weekly $0.5 \mathrm{ml}$ intravenous injections containing $5 \times 10^{8}$ leptospires and then bled.

Monospecific anti-hardjo and anti-pomona sera were kindly donated by Mr S Flint, ICI-Tasman $\mathbb{D}$ Ltd, Wellington, New Zealand. These were raised in :New Zealand White rabbits by repeated intravenous injections at 5-7 day intervals using increasing 1128 
volumes ( $1 \mathrm{ml}, 2 \mathrm{ml}, 4 \mathrm{ml}, 6 \mathrm{ml})$ from 4-6 day old cultures.

HUMAN SERA

These were obtained from patients displaying clinical symptoms of leptospirosis submitted by their medical practitioner.

MICROSCOPIC AGGLUTINATION TEST (MAT) This was performed in microtitre trays as outlined in the Manual of Clinical Immunology.?

PEROXIDASE CONJUGATES

Antirabbit immunoglobulins (lot 040) and antihuman-IgM (lot 120) and - JgG (lot 080A) conjugated to horseradish peroxidase were purchased from Dako, Copenhagen, Denmark. The titre used for DIG-ELISA using antirabbit immunoglobulins was $1 / 1000$ and for antihuman immunoglobulins $1 / 500$.

DIFFUSION IN GEL-ENZYME-LINKED

IMMUNOASSAY (DIG-ELISA)

This was performed according to Elwing and Nygren $^{4} 5$ but with the following modifications. Standard bacteriological polystyrene Petri dishes $(8.5 \mathrm{~cm}$ diameter) were coated with $20.0 \mathrm{ml}$ of Wellcome antigen (consisting of $2.5 \times 10^{9}$ leptospires suspended in $0.85 \% \mathrm{NaCl}$ ) overnight at room temperature. The dishes were rinsed twice with distilled water and then coated with $20.0 \mathrm{ml}$ of $0.5 \%$ bovine serum albumin (BSA, Sigma fraction V) for $30 \mathrm{~min}$ at $37^{\circ} \mathrm{C}$. The dishes were washed twice with pH 7.2 phosphate-buffered saline (PBS) followed by coating with $20.0 \mathrm{ml}$ of PBS containing $1 \% \mathrm{wt} / \mathrm{vol}$ Noble Agar (Difco laboratories) and $0.1 \% \mathrm{wt} / \mathrm{vol} \mathrm{BSA}$. When the agar had set, wells ( $3 \mathrm{~mm}$ diameter) were punched into the agar using a number 1 cork borer. The agar plug was removed by vacuum and $20 \mu \mathrm{l}$ of test sera (diluted if necessary in PBS containing $0.5 \% \mathrm{wt} / \mathrm{vol} \mathrm{BSA}$ and $0.05 \%$ $\mathrm{vol} / \mathrm{vol}$ Tween 20 (Sigma)) added.

After overnight incubation at $37^{\circ} \mathrm{C}$, the agar was removed, the dishes washed thrice with PBS and then flooded with $10.0 \mathrm{ml}$ of PBS-BSA-Tween 20 diluted peroxidase conjugated antiserum. The dishes were then incubated at $37^{\circ} \mathrm{C}$ for $60 \mathrm{~min}$, rinsed twice with distilled water and then coated with $15.0 \mathrm{ml}$ of $1 \% \mathrm{wt} /$ vol agarose (BDH) in $\mathrm{pH} 7 \cdot 0$ phosphate buffer $(0 \cdot 1 M)$ containing $0 \cdot 1 \% \mathrm{wt} / \mathrm{vol}$ of the substrate $p$-phenylenediamine dihydrochloride (BDH) and $0.01 \% \mathrm{vol} / \mathrm{vol}$ hydrogen peroxide (AJAX) and further incubated at $37^{\circ} \mathrm{C}$ for $15 \mathrm{~min}$, after which the dark brown reaction zones were measured using engineering calipers (Mitutoyo, Japan).

\section{Results}

COMPARISON OF DIG-ELISA TITRES WITH

MAT TITRES USING ANTIRABBIT SERA

Using a chequerboard titration of antigen versus conjugate concentration it was found that a final concentration of $2.5 \times 10^{9}$ leptospires and a $1 / 1000$ dilution of peroxidase conjugate antirabbit immunoglobulins produced consistent well defined zones of reaction. A positive reaction was signified by the appearance of a dark brown zone, the diameter of which varied in size according to the antibody concentration of the serum. Those sera with high MAT titres had correspondingly larger zones of reaction as compared to sera with low MAT titres.

Table 1 compares the DIG-ELISA and MAT antibody titres for the bivalent and monovalent sera using threefold dilutions for DIG-ELISA and twofold dilutions for MAT. No direct relation between the titres of these two techniques was observed and this appeared to be related to the immunisation methods used in the production of the antisera. The bivalent antiserum exhibited a higher DIG-ELISA titre and vice versa for the monovalent sera. However the monovalent sera exhibited no serological cross-reactivity when using either homologous or heterologous antigens in the MAT. On the other hand the monovalent anti-pomona did cross react with both serovars at lower antibody titres when using DIG-ELISA. Preimmune rabbit serum was negative for both tests.

Table 1 Comparison of rabbit antileptospiral sera for differentiating hardjo and pomona

\begin{tabular}{llllll}
\hline $\begin{array}{l}\text { Antisera } \\
\text { to serovars hardjo } \\
\text { and pomona }\end{array}$ & \multicolumn{3}{l}{ Antigens (serovars) } & \\
\cline { 2 - 3 } \cline { 5 - 6 } & hardjo & & \multicolumn{2}{c}{ pomona } & \\
\cline { 2 - 3 } \cline { 5 - 6 } & MAT & DIG-ELISA & MAT & DIG-ELISA \\
\hline $\begin{array}{l}\text { Bivalent anti-hardjo } \\
\text { and anti-pomona }\end{array}$ & 800 & 32400 & 1600 & 32400 \\
$\begin{array}{l}\text { Anti-hardjo } \\
\text { Anti-pomona }\end{array}$ & 1600 & 3600 & & - \\
\hline
\end{tabular}

Sera were diluted threefold for DIG-ELISA and twofold for MAT from $1 / 400$ to $1 / 32400$. The antibody titre for MAT is expressed as the reciprocal of the highest serum dilution that resulted in $50 \%$ agglutination of leptospires. The DIG-ELISA reaction zones varied from $13.2 \mathrm{~mm}$ (for the $1 / 400$ dilution) to $4.0 \mathrm{~mm}$ for the $1 / 32400$ dilution.

MAT = microscopic agglutination test.

DIG-ELISA = diffusion in gel-enzyme-linked immunosorbent assay.

COMPARISON OF DIG-ELISA TITRES WITH

MAT TITRES USING PATIENT SERA

The antibody titres of patients' serum measured by both MAT and DIG-ELISA are shown in Tables 2 , 3 and 4. In all serum samples examined the DIG- 
Table 2 Comparison of antibody titres in human sera as determined by MAT and DIG-ELISA tests with serovars hardjo and pomona

\begin{tabular}{|c|c|c|c|c|c|c|c|}
\hline \multirow[t]{4}{*}{ Human sera } & \multirow[t]{4}{*}{ Days between specimens } & \multicolumn{6}{|c|}{ Serological titres } \\
\hline & & \multicolumn{2}{|l|}{$M A T$} & \multicolumn{4}{|c|}{$D I G-E L I S A$} \\
\hline & & \multirow[t]{2}{*}{ hardio } & \multirow[t]{2}{*}{ pomona } & \multicolumn{2}{|l|}{ hardjo } & \multicolumn{2}{|c|}{ pomona } \\
\hline & & & & $\operatorname{Ig} M$ & $\operatorname{Ig} G$ & $\operatorname{Ig} M$ & $\operatorname{Ig} G$ \\
\hline$A_{1}$ & 0 & 100 & - & 400 & 100 & - & 100 \\
\hline A, & 14 & 200 & - & 1600 & 400 & $\ldots$ & 400 \\
\hline $\mathbf{B}_{1}$ & 0 & 800 & - & 6400 & 400 & 1600 & 400 \\
\hline $\mathbf{B}_{2}$ & 8 & 200 & - & 6400 & 1600 & - & 400 \\
\hline$C_{1}$ & 0 & 200 & - & 1600 & - & 400 & 100 \\
\hline $\mathrm{C}_{2}$ & 19 & 100 & - & 1600 & 100 & 400 & 100 \\
\hline $\mathrm{D}_{1}$ & 0 & 400 & -- & 6400 & $\ldots$ & $\ldots$ & - \\
\hline $\mathrm{D}_{2}$ & 11 & 200 & - & 1600 & - & - & - \\
\hline $\mathrm{D}_{3}$ & 20 & 200 & - & 1600 & - & 一 & - \\
\hline $\mathrm{E}_{1}$ & 0 & 400 & - & 6400 & 400 & 400 & 100 \\
\hline $\mathrm{E}_{2}$ & 18 & 400 & - & 6400 & 400 & 400 & 400 \\
\hline$F_{1}$ & 0 & - & - & 100 & - & - & - \\
\hline $\mathbf{F}_{2}$ & 7 & 200 & - & 6400 & 400 & 400 & - \\
\hline $\mathrm{G}_{1}$ & 0 & - & 400 & 1600 & 100 & 6400 & 1600 \\
\hline $\mathrm{G}_{2}$ & 21 & - & 800 & 400 & - & 6400 & 1600 \\
\hline $\mathrm{H}_{1}$ & 0 & - & 400 & - & - & 6400 & 100 \\
\hline $\mathrm{H}_{2}$ & 18 & - & 200 & 400 & - & 6400 & 400 \\
\hline${ }^{*} I_{1}$ & 0 & - & - & 400 & - & 1600 & - \\
\hline $\mathrm{I}_{2}$ & 18 & 一 & 50 & 400 & - & 1600 & - \\
\hline$I_{3}$ & 38 & - & 50 & $\ldots$ & $\ldots$ & 1600 & 400 \\
\hline$\dagger J_{1}$ & 0 & - & - & - & - & - & - \\
\hline $\mathbf{J}_{2}$ & 21 & - & - & - & - & $\cdots$ & - \\
\hline
\end{tabular}

Sera were diluted fourfold for DIG-ELISA and twofold for MAT.

$-=$ no detectable antibody.

*Positive culture obtained.

$\dagger J_{1}$ and $J_{2}$ were negative control sera collected from a 9 month child.

The MAT titre is expressed as the reciprocal of the highest serum dilution that resulted in $50 \%$ agglutination of leptospires. The DIG-ELISA titre is expressed as the reciprocal of the highest serum dilution that exhibited a zone of reaction greater than $4.0 \mathrm{~mm}$.

Table 3 Comparison of the results of MAT and IgM-DIG-ELISA tests using undiluted human sera positive to serovar hardjo

\begin{tabular}{lclc}
\hline MAT titre & No of sera & $\begin{array}{l}\text { Mean zone diameter }(\mathrm{mm}) \text { tested } \\
\text { against serovars }\end{array}$ \\
\cline { 3 - 4 } & & hardjo & pomona \\
\hline$<25$ & 10 & $4 \cdot 6$ & $4 \cdot 1$ \\
25 & 2 & $10 \cdot 1$ & $9 \cdot 5$ \\
50 & 4 & $11 \cdot 4$ & $10 \cdot 8$ \\
100 & 6 & $12 \cdot 3$ & $12 \cdot 1$ \\
200 & 7 & $13 \cdot 1$ & $11 \cdot 8$ \\
400 & 4 & $13 \cdot 5$ & $11 \cdot 5$ \\
800 & 2 & $14 \cdot 0$ & $11 \cdot 2$ \\
\hline
\end{tabular}

ELISA results reflected the MAT results with regard to the respective serovar titres. The DIG-ELISA titres were consistently greater than MAT titres, and this sensitivity allowed the early detection of two cases of leptospirosis (samples $F_{1}$ and $I_{1}$ ) which were initially negative by MAT. However this sensitivity was accompanied by extreme serological cross-reactivity at lower titres which only disappeared when titred out. Antibodies detected by DIG-ELISA were shown to belong predominantly to the IgM class. This observation was also confirmed by IgM indirect immunofluorescence and
Table 4 Comparison of the results of MAT and IgM-DIG-ELISA tests using undiluted human sera positive to serovar pomona

\begin{tabular}{|c|c|c|c|}
\hline \multirow[t]{2}{*}{$M A T$ titre } & \multirow[t]{2}{*}{ No of sera } & \multicolumn{2}{|c|}{$\begin{array}{l}\text { Mean zone diameter }(\mathrm{mm}) \text { tested } \\
\text { against serovars }\end{array}$} \\
\hline & & hardjo & pomona \\
\hline$<25$ & 10 & $4 \cdot 6$ & $4 \cdot 1$ \\
\hline 25 & 3 & $9 \cdot 6$ & $10 \cdot 2$ \\
\hline 50 & 5 & $11 \cdot 0$ & $11 \cdot 8$ \\
\hline 100 & 3 & $12 \cdot 1$ & $12 \cdot 5$ \\
\hline 200 & 3 & 11.4 & $13 \cdot 1$ \\
\hline 400 & 2 & $11 \cdot 8$ & $13 \cdot 5$ \\
\hline 800 & 1 & $11 \cdot 5$ & $14 \cdot 2$ \\
\hline
\end{tabular}

raised IgM titres were observed to exist for as long as 38 days in sample $I_{3}$. IgG antibody titres were lower and generally not observed until later in the course of the disease.

\section{Discussion}

The quantification of antibodies by DIG-ELISA is 0 based on the ability of antibodies to diffuse from $\overparen{D}$ wells in gel forming a diffusion gradient over an $\stackrel{\mathcal{P}}{+}$ antigen coated polystyrene surface. The antigen- $\square$ antibody complex is then made visual by means of a 
colour reaction which is formed by an enzymeconjugated anti-immunoglobulin reacting with its substrate-containing gel which is finally poured over the polystyrene surface. ${ }^{5}$ This technique was shown to detect and differentiate both hardjo and pomona antibodies in rabbit and human antisera. Whereas MAT detects antibodies to surface agglutinins only, DIG-ELISA detects antibodies to both surface and cytoplasmic antigens. Thus the different sensitivities of these two serological tests appeared to reflect the predominant class of immunoglobulin produced by whichever method of immunisation was used. It has been demonstrated previously that rabbit antiserum produced solely by intravenous inoculations of whole leptospires produced antibodies of mainly the IgM class (those that are efficient agglutinators), whereas antiserum produced by both intramuscular and intravenous inoculations, with or without oiladjuvant, produced antibodies of both IgM and IgG classes. ${ }^{7}$ It is thought that this could explain the differences in antibody titres of the monovalent and bivalent rabbit antisera detected by the MAT and DIG-ELISA techniques.

Extensive serological cross-reactivity between serovars hardjo and pomona was evident at lower titres when using DIG-ELISA. This serological cross-reactivity due to common antigens has prompted an investigation into the possibility of using strains of the saprophytic species Leptospira biflexa to screen patients' sera by this technique, as is done with other genus-specific serological tests such as the complement fixation test and haemagglutination.

The results also suggest that DIG-ELISA has several advantages over the traditional MAT:

(i) it is a simpler test to read requiring only the measurement of the diameter of the reaction zone, which is directly proportional to the concentration of antibodies in the serum being tested so that the serum need not be serially diluted.

(ii) it appears to be more sensitive than the MAT and can differentiate specific antibodies of the two main immunoglobulin classes.

(iii) its versatility in that antigen-coated plates can be made in batches and either stored at $-20^{\circ} \mathrm{C}$ indefinitely or coated in agar and stored at $4{ }^{\circ} \mathrm{C}$ for up to 1 month. The system has been applied to toxoplasma and cytomegalovirus serology both (unpublished observations) and found to be satisfactory.

(iv) its ease of standardisation using commercially available antigens and serum of known titre, since all zones of reaction greater than a negative serum are regarded as positive.

The authors wish to acknowledge the interest displayed and the help given by Dr J Penniket, Department of Health, Hamilton, New Zealand.

\section{References}

${ }_{1}^{1}$ Turner LH. Leptospirosis. Br Med J 1973;i:537-40.

${ }^{2}$ Ellinghausen HC, Top FH. Leptospirosis. In: Top FH, Wehrle PF, eds. Communicable and infectious diseases. Saint Louis: CV Mosby, 1976:395-409.

${ }^{3}$ Alexander AD. Leptospira. In: Lennette EH, Barlows A, Hausler WJ, Truant JP, eds. Manual of clinical microbiology. Washington DC: American Society of Microbiology, 1980:376-82.

${ }^{4}$ Elwing $\mathrm{H}$, Nygren $\mathrm{H}$. Diffusion in gel-enzyme linked immunosorbent assay (DIG-ELISA): a simple method for quantitation of class-specific antibodies. J Immunol Methods 1979;31:101-7.

${ }^{5}$ Elwing $\mathrm{H}$, Lange S, Nygren $\mathrm{H}$. Diffusion in gel-linked immunosorbent assay (DIG-ELISA): optimal conditions for quantitation of antibodies. J Immunol Methods 1980;38:247-56.

- Tennent RB. Diagnosis and treatment of leptospirosis. New Ethicals 1980;17:77-82.

7 Alexander AD. Serological diagnosis of leptospirosis. In: Rose NR, Friedman $\mathrm{H}$, eds. Manual of clinical immunology. Washington DC: American Society of Microbiology, 1980:542-6.

${ }^{8}$ Adler B, Faine S. Serological and protective antibody responses of rabbits to leptospiral antigens. $J$ Med Microbiol 1978;11:401-9.

${ }^{9}$ Adler B, Faine S. The antibodies involved in the human immune response to leptospiral infection. J Med Microbiol $1978 ; 11: 387-400$.

Requests for reprints to: Dr RTM Cursons, Pathology Department, Waikato Hospital, Private Bay, Hamilton, New Zealand. 